\title{
Distribution of immunoglobulin heavy chains in diseased synovia
}

\author{
AJ FREEMONT,* C RUTLEY† \\ From the Departments of ${ }^{*}$ Rheumatology and $\nmid$ Pathology, University of Manchester Medical School, \\ Manchester
}

SUMMARY Synovium from 142 patients with 12 different arthropathies was examined for the distribution of $\alpha, \delta, \gamma$, and $\mu$ immunoglobulin heavy chains. A high proportion of plasma cells in the superficial subintima in all diseases reacted for $\alpha$ heavy chains. Only in rheumatoid disease did the synovium contain more than $10 \%$ of plasma cells reacting for $\mu$ heavy chains.

The presence of plasma cells in the subintimal synovium of patients with inflammatory arthropathies is thought to be indicative of local immunoglobulin synthesis. ${ }^{1}$ The proportion of the various types of immunoglobulin and the various subclasses of plasma cells in the synovium have been reported as varying in different diseases, ${ }^{2-4}$ and it has been suggested that this may be a reflection of differing underlying pathogenetic mechanisms. To date, most comparative studies have been limited by the need to use fluorescence techniques on fresh frozen tissue, thus restricting the number of cases and diseases that can be examined at any one time. Newer enzyme based immunochemical methods permit greater flexibility as they can be applied to routinely processed stored specimens, providing that the antigenic sites to be examined have not been irreversibly masked by fixation. ${ }^{5}$

In this study we used such a technique to examine the distribution of different intracellular and extracellular immunoglobulin subclasses in the synovium of patients with various different arthropathies.

\section{Material and methods}

Synovium was obtained from 142 patients, 39 with rheumatoid disease, 26 with osteoarthritis, nine with ankylosing spondylitis, seven with tuberculous arthritis, 11 with septic arthritis, eight with psoriatic arthritis, six with systemic lupus erythematosus, three with systemic sclerosis, seven with Reiter's disease, 10 with gout, five with pyrophosphate deposition disease, and 11 with traumatic arthritis.

Diagnoses were based on standard clinical, serological, bacteriological, histological, and radiological

Accepted for publication 6 February 1986 criteria. All patients with rheumatoid arthritis were seropositive, and in the cases of infective arthritis the organism was identified both histologically and by culture of either the synovial fluid or synovium.

The patients were not matched for age, sex, duration of disease, or drug treatment, although no patient was receiving steroids, "second line" drug treatment, or antibiotics at the time of biopsy.

Biopsy specimens came from clinically diseased knees, ankles, or wrists and were obtained at open biopsy, synovectomy, or joint replacement, with the exception of one arthroscopic biopsy specimen from a patient with ankylosing spondylitis and necropsy specimens taken within 10 hours of death from two patients with systemic lupus erythematosus and two with gout.

Samples of synovium fixed in $10 \% \mathrm{v} / \mathrm{v}$ neutral buffered formalin and embedded in paraffin wax were sectioned at $4 \mu \mathrm{m}$. One section was stained with haematoxylin and eosin in a standard way, and four serial sections were stained for immunoglobulin heavy chains using the peroxidase-antiperoxidase immunoperoxidase technique. For this $\beta$ sections were deparaffinised and immersed in $95 \% \mathrm{v} / \mathrm{v}$ ethanol in water to each $100 \mathrm{ml}$ of which had been added $0.3 \mathrm{ml}$ of $\mathrm{H}_{2} \mathrm{O}_{2}$. They were then washed in $0.5 \mathrm{M}$ Tris buffered saline pH 7.5 (TBS), transferred to distilled water at $37^{\circ} \mathrm{C}$ for two minutes, and then to a trypsin solution at $37^{\circ} \mathrm{C}$ for 20 minutes. The trypsin solution was made by dissolving $100 \mathrm{mg}$ of crude porcine pancreatic trypsins (Sigma) and $100 \mathrm{mg}$ of calcium chloride in $100 \mathrm{ml}$ of TBS. After this the sections were washed in TBS and immersed for five minutes in a $20 \% \mathrm{v} / \mathrm{v}$ solution of normal swine serum in TBS. The serum was tipped off and optimally diluted primary antisera applied. The primary antibodies were rabbit 
antihuman $\alpha, \delta, \gamma$, and $\mu$ heavy chain antibodies (Dako) used at dilutions of $1 / 500(\alpha, \gamma$, and $\mu$ ) and $1 / 300(\delta)$ in phosphate buffered saline. Sections were incubated with primary antibody in a humid chamber at room temperature for $\mathbf{4 0}$ minutes, washed in TBS, immersed in normal swine serum, wiped, and the secondary antibody applied. The secondary antibody consisted of a $1 / 50$ solution of swine antirabbit immunoglobulins (Dako) in phosphate buffered saline at $\mathrm{pH} 7.4$ and was applied for 15 minutes, following which the sections were washed in TBS, immersed in normal swine serum, wiped, and a rabbit peroxidaseantiperoxidase solution (1/100 dilution of Dako PAP in phosphate buffered saline) applied for a further 15 minutes. The sections where then washed in TBS and immersed in a filtered solution of $50 \mathrm{mg}$ of 3,3 , diaminobenzidine tetra hydrochloride (DAB) in $100 \mathrm{ml}$ TBS containing $15 \mu$ l of 100 volume $\mathrm{H}_{2} \mathrm{O}_{2}$ for five minutes. The sections were washed thoroughly in cold running tap water, counterstained with haematoxylin, dehydrated, cleared, and mounted. Primary antibody free negative controls and positive controls of chronically inflamed colonic mucosa were included in every staining run.

The number of plasma cells reacting for each of the heavy chains was counted over equivalent areas in each of the serial sections. Counting was achieved using a square eyepiece graticule, which, at a nominal machine magnification of $200 \times$, covered an area on the specimen of $0.25 \mathrm{~mm}^{2}$. The top of the graticule was placed at the lower margin of the synoviocyte layer (counts being taken only from beneath an intact intima), and the number of stained plasma cells within the margins of the square were counted. Fifteen adjacent squares comprised the study area. This protocol was chosen because it enabled the study area to be standardised in each biopsy; it permitted arthroscopic and full thickness biopsy specimens to be compared, and it eliminated the errors introduced by counting within acellular surface deposits of fibrin.

\section{Results}

In sections stained with haematoxylin and eosin the spectrum of synovial changes seen in the various arthropathies was similar to those reported by others. $^{6-8}$ It was often impossible to distinguish between the various inflammatory arthropathies and to differentiate osteoarthrosis from traumatic synovitis simply by examination of the haematoxylin and eosin histology.

With the immunoperoxidase technique specific staining was seen in three sites; plasma cells, subintimal extracellular matrix, and, in rheumatoid disease only, surface synoviocytes. For the most part extracellular stain density varied with the number of

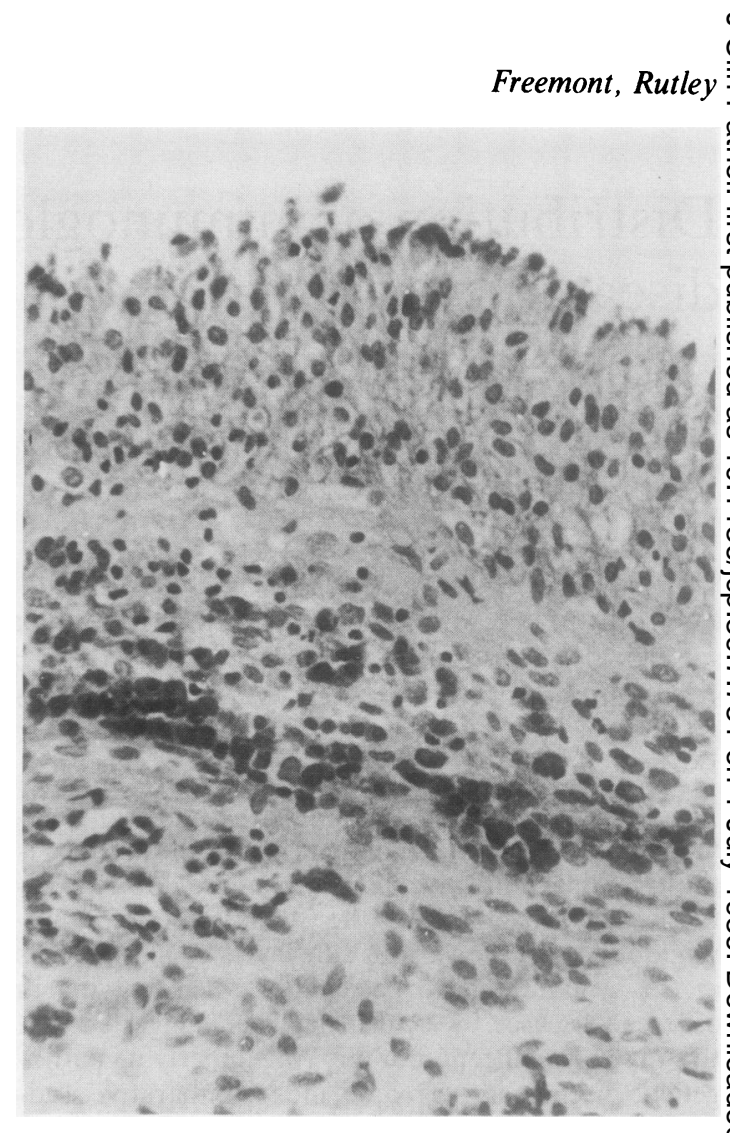

Fig. 1 Rheumatoid synovium stained for $\mu$ heavy chains.

Reacting plasma cells are seen in band like inflammatory cell infiltrate in superficial subintima.

(Peroxidase-antiperoxidase.) $\times 200$.

stained plasma cells.

Staining for constituents of their cytoplasm in this way accentuated the pattern of plasma cell distribu - . tion. Plasma cells were found between the granu-ô lomata in tuberculous lesions, admixed with poly- $₹$ morphs in septic arthritis and as part of occasional, subintimal, and capsular lymphoplasmacytic aggre- $>$ gates in systemic sclerosis, pyrophosphate deposition disease, gout, osteoarthritis, and traumatic arthritis. N In rheumatoid disease, ankylosing spondylitis, sys-temic lupus erythematosus, Reiter's disease, and 0 psoriatic arthritis plasma cells were present in the $\tilde{\omega}$ deep subintima and capsule but were most prominent in the superficial subintima in a band like zone paral-e lel with the surface and separated from surface syno- $\frac{\varnothing}{\Phi}$ viocytes by a relatively acellular layer of connective? tissue up to $50 \mu \mathrm{m}$ deep (Fig. 1). In ankylosing spon- $\frac{T}{-}$ dylitis and systemic lupus erythematosus the subin-

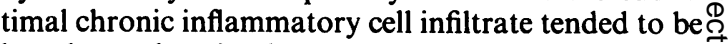
less dense than in rheumatoid disease, and in some $\stackrel{\mathbb{Q}}{\mathbb{Q}}$ examples of Reiter's disease the infiltrate had ao particularly prominent polymorph component. 
Distribution of immunoglobulin heavy chains in diseased synovia

Table No of plasma cells reacting for different subclasses of immunoglobulin heavy chains in various arthropathies (mean plasma cell numbers in study area including highest and lowest in parentheses where applicable).

\begin{tabular}{|c|c|c|c|c|c|c|}
\hline \multirow[t]{2}{*}{ Diagnosis } & \multirow{2}{*}{$\begin{array}{l}\text { No of } \\
\text { cases }\end{array}$} & \multirow[t]{2}{*}{ Total } & \multicolumn{4}{|c|}{ Immunoglobulin heavy chain } \\
\hline & & & $\alpha$ & $\gamma$ & $\mu$ & $\delta$ \\
\hline $\begin{array}{l}\text { Rheumatoid disease } \\
\text { Osteoarthritis } \\
\text { Ankylosing spondylitis } \\
\text { Tuberculous arthritis } \\
\text { Septic } \\
\text { Psoriatic arthritis } \\
\text { Reiter's } \\
\text { Systemic lupus erythematosus } \\
\text { Gout } \\
\text { Trauma } \\
\text { Pyrophosphate deposition disease } \\
\text { Systemic sclerosis }\end{array}$ & $\begin{array}{r}39 \\
26 \\
9 \\
7 \\
11 \\
8 \\
7 \\
6 \\
10 \\
11 \\
5 \\
3\end{array}$ & $\begin{array}{l}1978(583-3042) \\
102(0-514) \\
470(230-984) \\
139(81-197) \\
743(0-1419) \\
2112(707-3468) \\
650(18-1652) \\
390(15-1179) \\
443(0-1607) \\
33(4-104) \\
273(0-1341) \\
366(0-599)\end{array}$ & $\begin{array}{l}367(6-772) \\
29(0-118) \\
128(60-421) \\
51(29-73) \\
212(0-663) \\
457(134-1159) \\
154(3-267) \\
142(4-453) \\
158(0-673) \\
7(0-21) \\
93(0-396) \\
79(0-270)\end{array}$ & $\begin{array}{c}1061(405-2076) \\
72(0-439) \\
329(186-552) \\
74(35-100) \\
427(0-738) \\
1589(444-2752) \\
466(11-1293) \\
243(10-715) \\
278(0-906) \\
23(0-86) \\
175(0-688) \\
200(0-502)\end{array}$ & $\begin{array}{c}341(17-764) \\
0 \cdot 5(0-2) \\
14(10-21) \\
13(9-19) \\
5(0-26) \\
29(21-39) \\
20(0-63) \\
6(0-15) \\
6(0-27) \\
3(0-12) \\
3(0-15) \\
7(0-10)\end{array}$ & $\begin{array}{l}5(0-18) \\
0(-) \\
0(-) \\
0(-) \\
3(0-17) \\
2(0-6) \\
10(0-23) \\
0(-) \\
4(0-18) \\
0(-) \\
2(0-9) \\
0(-)\end{array}$ \\
\hline
\end{tabular}

The total number of plasma cells (Table) varied considerably between biopsy specimens, including those from patients in the same disease group. The mean number of plasma cells was highest for the rheumatoid and psoriatic patients, and these two groups contained all those biopsy specimens in which the total number of plasma cells in the study area exceeded 2000. These biopsy specimens constituted $62 \%$ of those in the group with rheumatoid diseases and $75 \%$ in the group with psoriasis.

Of the different subtypes of plasma cells, those reacting for $\gamma$ heavy chains were found most often in

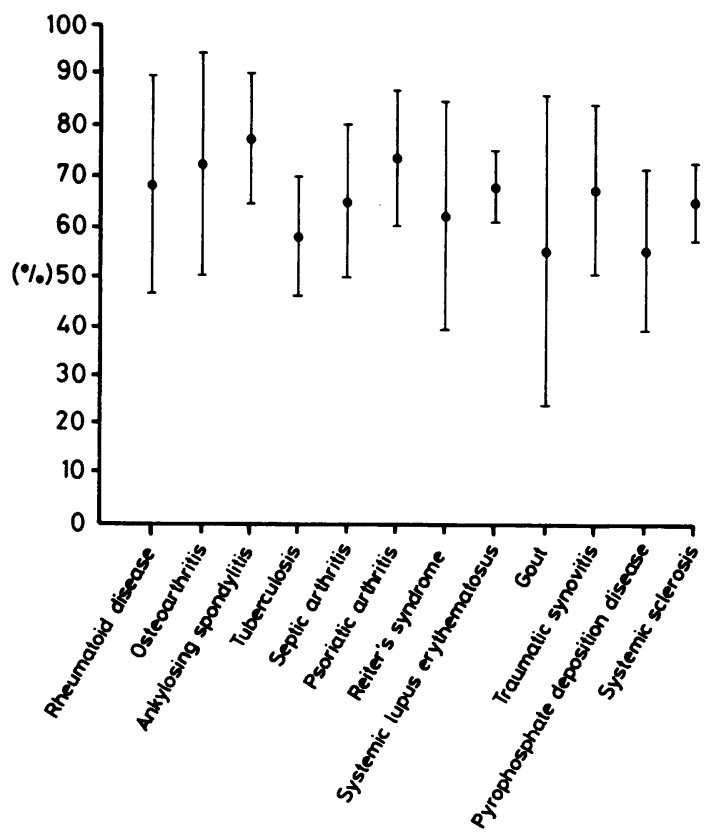

Fig. 2 Proportion of plasma cells reacting for $\gamma$ heavy chains (mean (ISD)). descending order of occurrence, by those containing $\alpha, \mu$, and $\delta$ chains. Overall, the percentage occurrence of the various subtypes was about $65 \%(\gamma), 30 \%(\alpha)$, $5 \%(\mu)$, and $<1 \%(\delta)$. Only the absolute number of $\mu$ heavy chain positive plasma cells showed any variation between the different arthropathies (Figs. 2, 3, 4 , and 5). All those biopsy specimens, in which there were more than $100 \mu \mathrm{m}$ positive cells in the study area $\left(3.75 \mathrm{~mm}^{2}\right)$, were from patients with rheumatoid disease. Similarly, all those patients in whom $10 \%$ or more of the plasma cells contained $\mu$ heavy chains also came from this group. These constituted $74 \%$ of the patients with rheumatoid disease.

Although the number of plasma cells reacting for $\delta$ heavy chains in any one biopsy was never high, some

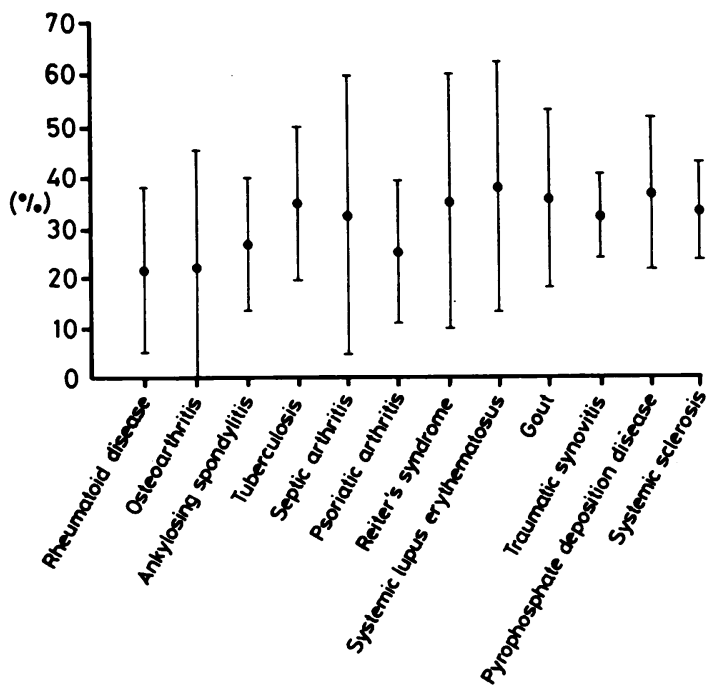

Fig. 3 Proportion of plasma cells reacting for $\alpha$ heavy chains (mean (ISD)). 


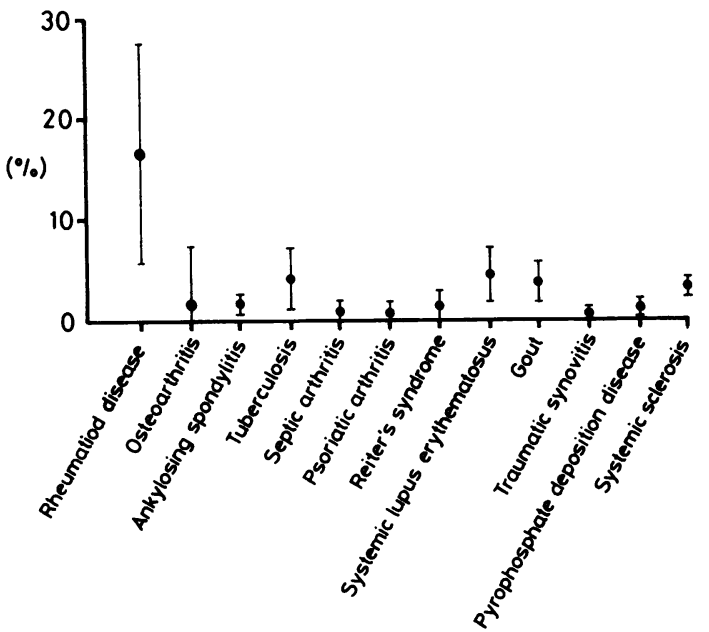

Fig. 4 Proportion of plasma cells reacting for $\mu$ heavy chains (mean (ISD)).

were seen in $\mathbf{4 4 \%}$ of patients with rheumatoid disease, $43 \%$ with Reiter's disease, $38 \%$ with psoriatic arthritis, $27 \%$ with septic arthritis, $20 \%$ with pyrophosphate deposition disease, and $10 \%$ with gout.

\section{Discussion}

This study investigated the different patterns of immunohistochemically detectable immunoglobulin heavy chains in diseased synovia of patients with a wide variety of arthropathies. As extracellular staining for heavy chains was unpredictable and quantitation too subjective to be reliable, we concentrated on the type and distribution of intracellular heavy chains. These were found mainly in cells with the typical morphology of plasma cells, and this was probably indicative of active immunoglobulin synthesis.

Cells putatively synthesising IgG, IgA, and IgM

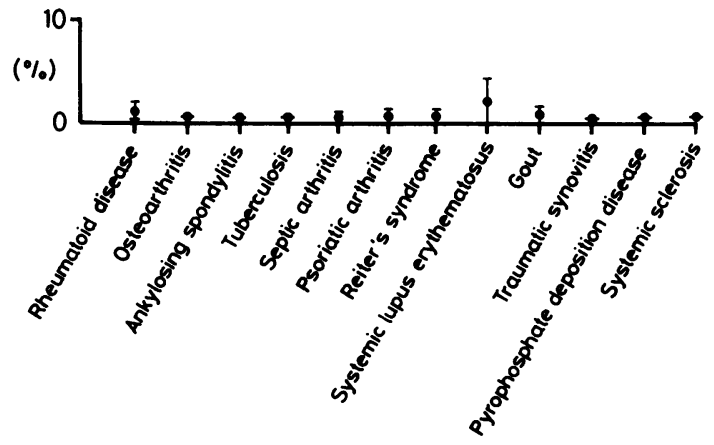

Fig. 5 Proportion of plasma cells reacting for $\delta$ heavy chains (mean (ISD)). were found in examples of all the arthropathies studied. Previous investigations of the distribution of $\overline{0}$

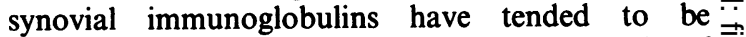
restricted to only a few diseases. When the results of these studies are compared the findings are sometimes $\overrightarrow{0}$ contradictory. IgG has been identified in synovia in $\underline{O}$ rheumatoid disease, ${ }^{1-59-15}$ systemic lupus ery- $\frac{\bar{\sigma}}{\sigma}$

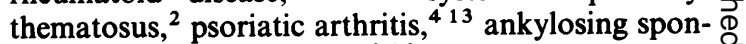
dylitis, ${ }^{5}$ and osteoarthritis. ${ }^{316}$ Intracellular IgA has also been shown in psoriatic arthritis ${ }^{13}$ and anky- ${ }^{\infty}$ losing spondylitis, ${ }^{5}$ but although IgA was found in $\vec{\circ}$ rheumatoid disease, in several studies, ${ }^{151214}$ in some $\overrightarrow{\vec{\omega}}$ it could not be identified. ${ }^{1017}$ All those authors who detected IgG also showed IgM in synovia, with the exception of Kinsella et al, ${ }^{11}$ who were unable to find ${ }_{\omega}$ IgM in rheumatoid disease, and Fehr etal, ${ }^{4}$ who could not show any in psoriatic arthritis.

Opinion regarding synovial immunoglobulin syn- $\omega$ thesis in Reiter's disease is divided. IgG has been $\mathrm{O}$ found by some workers ${ }^{217}$ but not others, ${ }^{11}{ }^{12}$ and IgA synthesis has been shown in one study ${ }^{18}$ but not $\sqsubset$ another. ${ }^{12}$

We identified IgD in the synovium in at least one $\vec{\bullet}$ case each of rheumatoid disease, psoriatic arthritis, $\infty$ gout, pyrophosphate deposition disease, Reiter's syndrome, and septic arthritis. The presence of IgDO seems only to have been investigated by Mestecky and Miller, ${ }^{17}$ who were unable to find any in rheu-o matoid synovium.

Although a few authors have commented on the $\stackrel{\mathbb{Q}}{\complement}$ proportions of various immunoglobulins in diseased $\overrightarrow{\overrightarrow{0}}$ synovium, this is one of the few studies which has set 3 out to formally quantify the ratio of the various? subtypes of plasma cells in a wide variety of? arthropathies. Rheumatoid disease seems to differ옹 from all other synovitides in that the synovium con-? tains a relatively high proportion of plasma cells syn- 3 . thesising IgM. This may be a reflection of the production of IgM rheumatoid factor by the inflamed $\frac{3}{3}$ synovial membrane, but the relative proportions of 0 cells synthesising different subclasses of rheumatoid factors and other immunoglobulins ${ }^{1920}$ indicate that in some patients this is not necessarily the case. For these patients, at least, the nature of the IgM syn- $\sim$ thesised by synovial plasma cells requires further evaluation.

The presence of a relatively high proportion of $\operatorname{IgA}$ positive plasma cells in diseased synovium is reminiscent of some mucosal surfaces. In these sites lymphocytes, which will eventually develop into $\operatorname{IgA} \stackrel{\odot}{\Phi}$ secreting plasma cells, selectively enter the tissue ${ }_{T}^{+}$ under specific local influences such as subsets of $T^{-}+{ }^{-}$ helper cells ${ }^{21}$ or macrophages, perhaps acting in- $\frac{\mathbb{D}}{\mathrm{D}}$ directly via vascular endothelium. ${ }^{22}$ The cellular $\frac{\rho}{\mathbb{D}}$ microenvironment of synovium may dictate lympho- $\_$ cyte entry in a way similar to that of other sites of $\operatorname{IgA} ?$ 
synthesis, and certainly, vessels similar to those seen in Peyer's patches have been described in inflamed synovium, ${ }^{23}$ but their selectivity for different subtypes of $\mathrm{T}$ and $\mathrm{B}$ lymphocytes are, as yet, unknown.

Because of its well recognised advantages the type of immunohistochemical technique used to disclose the distribution of immunoglobulin heavy chains in this study has allowed a large number of specimens to be examined under almost identical conditions. Analysis of the resulting permanent preparations has emphasised two characteristics of diseased synovia, which could not have been so easily identified using older techniques - the almost universal presence of a high proportion of IgA synthesising plasma cells and the large number of IgM positive cells in rheumatoid disease. Both give an insight into the pathogenesis and cellular interactions in synovial disease, and the second characteristic may be of diagnostic value.

This work was financially supported by grants from the Arthritis and Rheumatism Council and the Medical Research Council.

\section{References}

${ }^{1}$ Geiler G. The antibody synthesis of the synovial membrane in rheumatoid arthritis. In: Rheumatoid arthritis. New York: Academic Press, 1971:317-23.

${ }^{2}$ Brandt KD, Cathcart ES, Cohen AS. Studies of immune deposits in synovial membranes and corresponding synovial fluids. $J \mathbf{L a b}$ Clin Med 1968;72:631-47.

${ }^{3}$ Kushner I, Somerville JA. Permeability of human synovial membranes to plasma proteins. Relationship to molecular size and inflammation. Arthritis Rheum 1971;14:560-70.

${ }^{4}$ Fehr K, Velvart M, Rauber M, et al. Production of agglutinators and rheumatoid factors in plasma cells of rheumatoid and nonrheumatoid synovial tissues. Arthritis Rheum 1981;24:510-9.

${ }^{5}$ Revell PA, Mayston V. Histopathology of the synovial membrane of peripheral joints in ankylosing spondylitis. Ann Rheum Dis 1982;41:579-86.

${ }^{6}$ Fassbender HG. Pathology of rheumatic diseases. Berlin: SpringerVerlag, 1975.

${ }^{7}$ Eulderink F. The synovial biopsy. In: Berry CL, ed. Current topics in pathology. Vol 71. Bone and joint disease. Heidelberg: Springer-Verlag, 1982:25-72.

${ }^{8}$ Gardener DL. Pathology of the connective tissue diseases. London: Edward Arnold, 1965.

${ }^{9}$ Bayliss CE, Dawkins RL, Cullity G, Davies RE, Houliston JB. Laboratory diagnosis of rheumatoid arthritis. Ann Rheum Dis 1975;34:395-402.

${ }^{10}$ Fish AJ, Michael AF, Gewurtz H, Good RA. Immunopathologic changes in rheumatoid arthritis synovium. Arthritis Rheum 1966;9:267-78.

${ }^{11}$ Kinsella TD, Baum J, Ziff M. Studies of isolated synovial lining cells of rheumatoid and non-rheumatoid synovial membranes Arthrtis Rheum 1980;13:734-53.

12 Baldassare AR, Weiss TD, Tsai CC, Arthur RE, Moore TL, Zucker J. Immunoprotein deposition in synovial tissue in Reiter's syndrome. Ann Rheum Dis 1981;40:281-5.

${ }^{13}$ Fryand $O$. Immunological studies on synovial joint membranes in psoriatic arthritis. Acta Derm Venereol 1979;87:15-20.

${ }^{14}$ Cecere F, Lessard J, McDuffy S, Pope RM. Evidence for the local production and utilisation of immune reactants in rheumatoid arthritis. Arthritis Rheum 1982;25:1307-15.

${ }^{15}$ Cracchiolo A, Goldberg LS. Elution of antiglobulins and antinuclear antibody from rheumatoid synovial membrane. Ann Rheum Dis 1972;31:186-91.

${ }^{16}$ Pringle JA, Byers PD, Brown MEA. Immunofluorescence in osteoarthritis. Nature 1978;274:94.

${ }^{17}$ Mestecky J, Miller EJ. Presence of antibodies specific to cartilagetype collagen in rheumatoid synovial tissue. Clin Exp Immunol 1975;22:453-6.

${ }^{18}$ Yates DB, Maini RN, Scott JT, Sloper JC. Complement activation in Reiter's syndrome. Ann Rheum Dis 1975;34:468.

${ }^{19}$ Munthe E. Deposition of immune complexes in synovial membrane and fluid. In: Immunopathogenesis of rheumatoid arthritis. Reedbooks Limited, 1979:85-8.

${ }^{20}$ Egeland T, Lea T, Saari G, Mellbye OJ, Natvig JB. Quantitation of cells secreting rheumatoid factor of IgG, IgM and IgA class after elution from rheumatoid synovial tissue. Arthritis Rheum 1982;25:1445-50.

${ }^{21}$ Holmes JE. The role of $\mathrm{T}$ cells in immunoglobulin A production. University of Manchester, 1984. (Thesis).

22 Janossy G, Tidman N, Sleby WS, et al. Human T lymphocytes of inducer and suppressor type occupy different microenvironments. Nature 1980;288:81.

${ }^{23}$ Freemont AJ, Jones CJP, Bromley M, Andrews P. Changes in vascular endothelium related to lymphocyte collections in diseased synovia. Arthritis Rheum 1984;26:1427-33.

Request for reprints to: Dr AJ Freemont, Department of Rheumatology, University of Manchester, Stopford Building, Oxford Road, Manchester M13 9PT, England. 